\title{
Kinetic Study of the Oxidation of Catechols in the Presence of $\mathbf{N}$-Methylaniline
}

\author{
Lida Khalafi, ${ }^{1}$ Mohammad Rafiee, ${ }^{2}$ Maryam Shahbak, ${ }^{1}$ and Hamidreza Shirmohammadi ${ }^{2}$ \\ ${ }^{1}$ Department of Chemistry, Shahr-e-Qods Branch, Islamic Azad University, Tehran, Iran \\ ${ }^{2}$ Department of Chemistry, Institute for Advanced Studies in Basic Sciences (IASBS), Zanjan, Iran \\ Correspondence should be addressed to Lida Khalafi; 1_khalafi@yahoo.com
}

Received 23 June 2012; Revised 29 July 2012; Accepted 3 August 2012

Academic Editor: Alvin A. Holder

Copyright (c) 2013 Lida Khalafi et al. This is an open access article distributed under the Creative Commons Attribution License, which permits unrestricted use, distribution, and reproduction in any medium, provided the original work is properly cited.

\begin{abstract}
The reactions of electrochemically generated $o$-quinones from oxidation of catechol and 4-methylcatechol as Michael acceptors with $\mathrm{N}$-methylaniline as nucleophile have been studied using cyclic voltammetry. Voltammetric responses show that oxidation of catechols is followed by Michael addition of $\mathrm{N}$-methylaniline. The reaction products are believed to be diphenylamine derivatives of catechols that undergo electron transfer at more negative potentials than the catechols. The observed homogeneous rate constants $\left(k_{\mathrm{obs}}\right)$ for Michael addition were estimated by digital simulation and show that the reactivity of 4-methyluinone is considerably less than $o$-quinone. The oxidation potentials of the desired products drastically depend on the solution $\mathrm{pH}$ and their structures.
\end{abstract}

\section{Introduction}

Catechol is one of the common building blocks in organic synthesisand is produced in industrial scales as the precursor of pesticides, perfumes, and pharmaceuticals [1]. The catechol skeleton also occurs in a variety of natural products specially the antioxidant [2]. The most well-known characteristic of the catechols is that they can be easily oxidized mainly due to their antioxidant activity and low oxidation potentials [3]. The products of oxidation are the corresponding reactive and electron-deficient $o$-quinones. Considering their instability they can be produced only by in situ methods and mild oxidation of catechols. One of the most successful in situ generations of reactive $o$-quinones species is the electrochemical oxidation [4]. There are many reports on electrooxidation of catechols to produce $o$-quinones as reactive intermediates in many useful homogeneous reactions [5]. The Michael additions of aliphatic, aromatic, and benzylic amines to electrochemically generated $o$-quinone have been reported previously [6-8]. The reaction products of aromatic amines with $o$-quinones have been reported to be diphenylamine derivatives or their related quinonic forms. Diphenylamine is a parent compound of many derivatives, which are used for the production of dyes, perfumery, pharmaceuticals, photography chemicals, and further smallscale applications [9]. Its derivatives are also widely used as stabilizers in nitrocellulose-containing explosives, rubber and elastomer industry, and scald inhibitor as the result of their antioxidant properties [10]. Herein we would like to examine the electrochemical oxidation of two catechol derivatives in the presence of $\mathrm{N}$-methylaniline in kinetic and electrochemical details.

\section{Experimental}

2.1. Apparatus. Cyclic voltammetry and controlled-potential coulometry were performed using a Microautolab model PGSTAT 10 potentiostat/galvanostat. In the voltammetry experiments a glassy carbon disc $(1.8 \mathrm{~mm}$ diameter $)$ and a platinum wire were used as working and counter electrodes, respectively. The working electrode used in controlledpotential coulometry was an assembly of four carbon rods ( $6 \mathrm{~mm}$ diameter and $4 \mathrm{~cm}$ length) and large platinum gauze constituted the counter electrode. The working electrode potentials were measured versus SCE (all electrodes from AZAR electrode, Urmia, Iran). The working electrodes were mechanically polished with $\mathrm{Al}_{2} \mathrm{O}_{3}$. The homogeneous rate 
constants were estimated by analyzing the cyclic voltammetric responses using the CVSIM simulation software [11].

2.2. Reagents and Solutions. Catechol, 4-methylcatechol, and $\mathrm{N}$-methylaniline, reagent grade, were prepared from Aldrich and used as received. All other chemicals were of proanalysis grade from E. Merck. These chemicals were used without further purification. The stock solution of catechols and Nmethylaniline were prepared daily.

\section{Result and Discussion}

3.1. Voltammetric Study. Figure 1, curve a, shows the cyclic voltammograms of $1.0 \mathrm{mM}$ catechol in acetate buffer solution $\mathrm{pH}=5$. The cyclic voltammograms of catechol show one anodic $\left(A_{1}\right)$ and corresponding cathodic peak $\left(C_{1}\right)$ related to its transformation to $o$-quinone and vice versa. The peak current ratio nearly unity confirms the relative stability of produced $o$-quinone at this condition [8]. In the presence of 1.0 mM N-methylaniline and the same condition (Figure 1, curve b) the cathodic peak, related to reduction of $o$-quinone, disappears and a new cathodic peak $\left(\mathrm{C}_{2}\right)$ appears at more negative potentials. Also despite of electroinactivity of $\mathrm{N}$ methylaniline at this potential range, the height of anodic peak increases considerably.

This finding, changes in voltammetric responses, and the previously reported papers [5] are indicative of an ECE mechanism for the electrode reaction. The nomenclature $E$ is used for an electron transfer reaction and $C$ for a chemical reaction and their order is indicative of the order of reactions. Then ECE mechanism consists of an electron transfer reaction (E) followed by a chemical reaction $(\mathrm{C})$ that the product of this reaction is electroactive to and undergoes the electron transfer (E) at the electrode surface. This reaction mechanism has some diagnostic criteria which are obtained by voltammetric study at various scan rates or experiment time scale [12]. Voltammetric study at various scan rates (Figure 2(I)) shows that by augmentation of scan rate the height of both anodic and cathodic peaks increases, but the increase in $\mathrm{C}_{1}$ height is more than expected for diffusion controlled electrode reaction. On the other hand the anodicto-cathodic peaks current ratio raises parallel to increase in scan rate. At high scan rates the time scale and extent of reaction decrease, then the remaining o-quinone and the height of cathodic peak increase. This confirms the reactivity of produced $o$-quinone from oxidation of catechol toward $\mathrm{N}$ methylaniline.

Normalized cyclic voltammograms are obtained by dividing the current of cyclic voltammograms by the square root of the scan rate [13]. Multiple files at different scan rates can be normalized and overlaid for obtaining more information. In Figure 2(II), the normalized voltammograms show that proportional to the decreasing of potential sweep rate the height of $A_{1}$ peak increases. Oxidation of the reaction product at the electrode surface causes to increase in anodic peak currents and the current function for $A_{1}$ peak $\left(\operatorname{Ip}_{\mathrm{Al}} / \mathrm{v}_{1 / 2}\right)$ increases with decreasing the scan rate. Also, Figure 2(II) shows that anodic peak $\left(A_{1}\right)$ potentials shift to more negative values

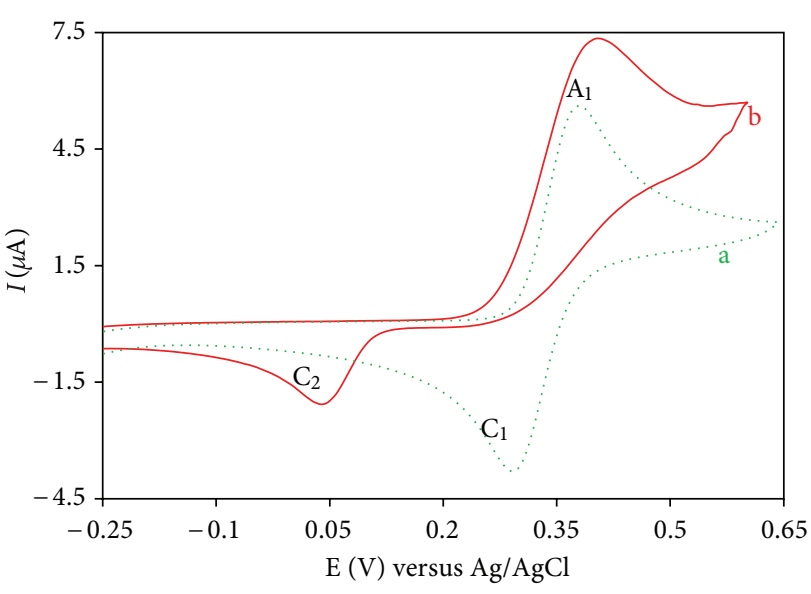

Figure 1: Cyclic voltammograms of $1.0 \mathrm{mM}$ catechol (a) in the absence and (b) in the presence of $1.0 \mathrm{mM} \mathrm{N}$-methylaniline in acetate buffer solution $(\mathrm{pH}=5, \mathrm{c}=0.15 \mathrm{M})$ at glassy carbon electrode; scan rate: $50 \mathrm{mV} \mathrm{s}^{-1}$.

at low scan rates [13]. Finally the multicyclic voltammetry (Figure 2(III)) of the solution shows that a new anodic peak $\left(\mathrm{A}_{2}\right)$ as the counter part of $\mathrm{C}_{2}$ appears in the second cycle. All of these results are in good agreement with the proposed ECE mechanism for this reaction.

The oxidation of 4-methylcatechol as a simple substituted catechol has been studied at the same condition of catechol. Figure 3 shows the normalized cyclic voltammograms of 1.0 mM solution of 4-methylcatechol and $\mathrm{N}$-methylaniline. It also clearly shows that at very high scan rate only the electrochemical responses of catechol and $o$-quinone appear in voltammograms, whereas by decreasing scan rate and more extent of chemical reaction the $A_{2}$ and $C_{2}$ peaks related to the reaction products appear and their heights increase. The proposed mechanism is presented in Scheme 1.

Consumption of 4 electrons per molecule of catechol in controlled potential coulometry and the mass spectra of the products support the proposed reaction mechanism. The ${ }^{1} \mathrm{H}$ and ${ }^{13} \mathrm{C}$ NMR of products (not isolated) confirm the possibility of formation of final products. For example the parent peak of 4-methylcatechol and N-methylaniline product appears in $229 \mathrm{~m} / \mathrm{z}$. As shown, all of these reaction steps depend on the solution $\mathrm{pH}$ and kinetic study of the reactions was extended at various $\mathrm{pH}$ values. Figure 4 shows that the anodic-to-cathodic peak current ratio, the reactivity, increases drastically from the $\mathrm{pH}$ values 4 to 6 and after that decreases slightly. Considering the $\mathrm{pK}_{a}$ value of $\mathrm{N}$ methylaniline (4.9 at this ionic strength [14]) at the $\mathrm{pH}$ values less than 5 the dominant form of $\mathrm{N}$-methylaniline is the protonated ammonium form; it is not the suitable form for the Michael addition reaction.

Also the comparison of electrochemical studies of catechol and 4-methylcatechol (Figure 5) indicates that the reactivity of catechol, the ratio of $\mathrm{C}_{2}$ over $\mathrm{C}_{1}$ at the same condition, is considerably more than 4 -methylcatechol. This is related to the steric effect of methyl group and occupation of one positions of catechol with the methyl group that 

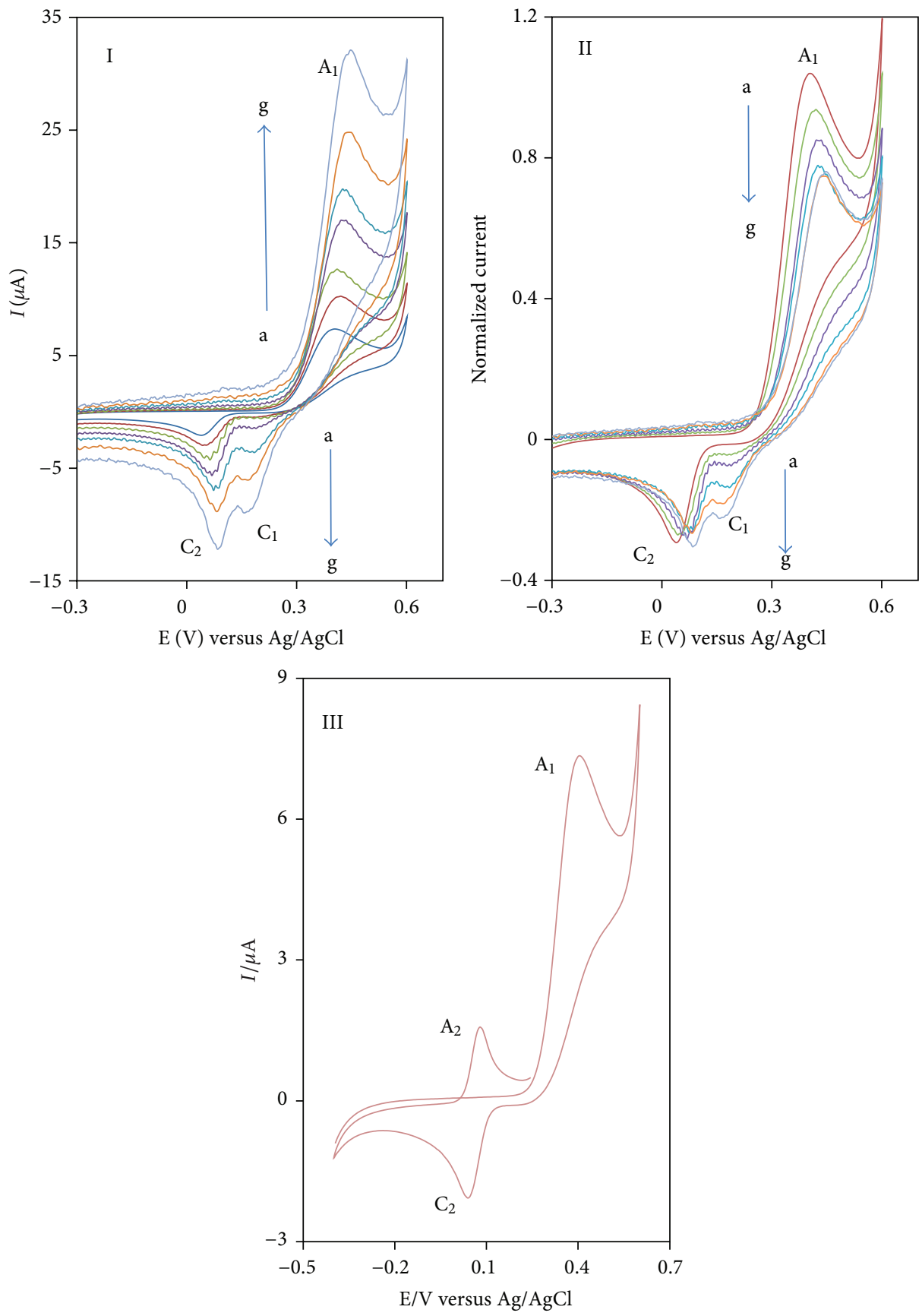

FIGURE 2: (I) Cyclic voltammograms and (II) normalized cyclic voltammograms of $1.0 \mathrm{mM}$ catechol in the presence of $1.0 \mathrm{mM}$ Nmethylaniline in acetate buffer solution $(\mathrm{pH}=5, \mathrm{c}=0.15 \mathrm{M})$ at various scan rates; scan rate from (a) to $(\mathrm{g})$ are 50, 100, 200, 400, 700, 1100, and $1600 \mathrm{mV} \mathrm{s}^{-1}$. (III) Multicyclic voltammograms with scan rate $50 \mathrm{mV} \mathrm{s}^{-1}$.

reduced the probability of reaction by half. The other striking result to emerge from this comparison is the difference in half-wave potentials $\left(\Delta E_{1 / 2}\right)$ of reactant and products. It is expected that the $E_{1 / 2}$ of diphenylamines is less than catechols due to resonance electron-donating character of arylamine group.

Despite the same functional group that is attached to the catechols; the $E_{1 / 2}$ of catechol product is $210 \mathrm{mV}$ less than catechol's one, whereas the $E_{1 / 2}$ for the product of 4-methylcatechol is $95 \mathrm{mV}$ less than it. Presence of methyl group on the neighborhood position of amine group forced it to the out of plane conformation that diminishes the possibility of resonance and electron donating possibility [15].

3.2. Kinetic Evaluation. The schemes for the electrochemical oxidation of catechol and 4-methylcatechol in the presence 


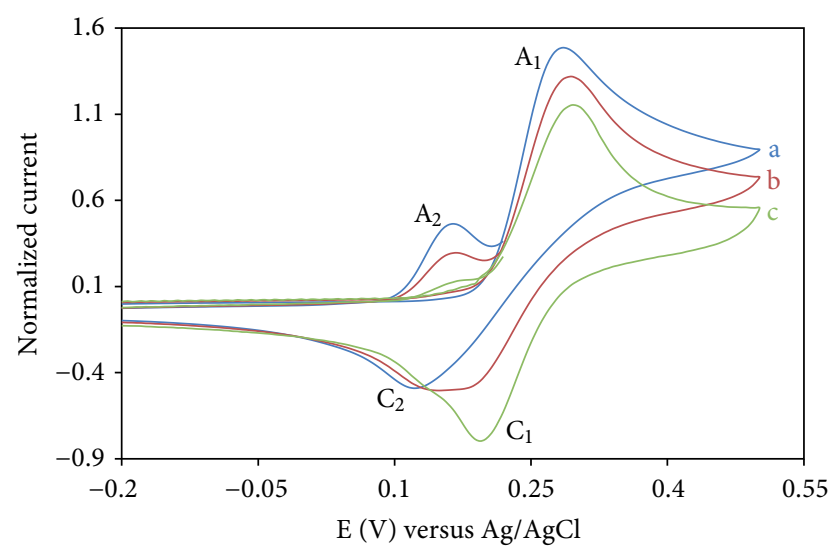

FIgURE 3: Normalized cyclic voltammograms of $1.0 \mathrm{mM} \mathrm{4-}$ methylcatechol and 1.0 mM N-methylaniline in acetate buffer solution $(\mathrm{pH}=5, \mathrm{c}=0.15 \mathrm{M}$ ) at various scan rates; scan rate from (a) to (c) are 50, 400, and $2200 \mathrm{mV} \mathrm{s}^{-1}$.<smiles>[R][R]=C1C=CC(=O)C(=O)C=C1[R]</smiles><smiles>[R]C1=CC(=O)C(=O)C=CC1=O</smiles><smiles>[R]C1=CC(=O)C(=O)C=C1N(C)c1ccccc1</smiles>

SCHEME 1

of $\mathrm{N}$-methylaniline were proposed and tested by diagnostic criteria of cyclic voltammograms. For more details the homogeneous rate of chemical reaction and formation of diphenylamine were studied by digital simulation. The simulation was carried out based on ECE mechanism and assuming semiinfinite one-dimensional diffusion on a planar electrode. The experimental parameters entered for digital simulation consist of the following: starting potential $\left(E_{\text {start }}\right)$, switching potential $\left(E_{\text {switch }}\right)$, scan rate $(v)$, half wave potential $\left(E_{1 / 2}\right)$, and analytical concentration of species. The transfer coefficients $(\alpha)$ and heterogeneous rate constants for oxidation of catchols are also entered as known parameters [16]. All these parameters were kept constant and the observed rate constant of chemical reaction $k_{\mathrm{obs}}$ was allowed to change during the fitting processes. The fitting consists of finding a rate constant for which the differences between the digitally simulated and the experimental data reach to minimum. The rate constants of the reaction were estimated for various $\mathrm{pHs}$ and scan rates. The relative standard deviations were obtained for each individual rate constant at 4 various scan rates.

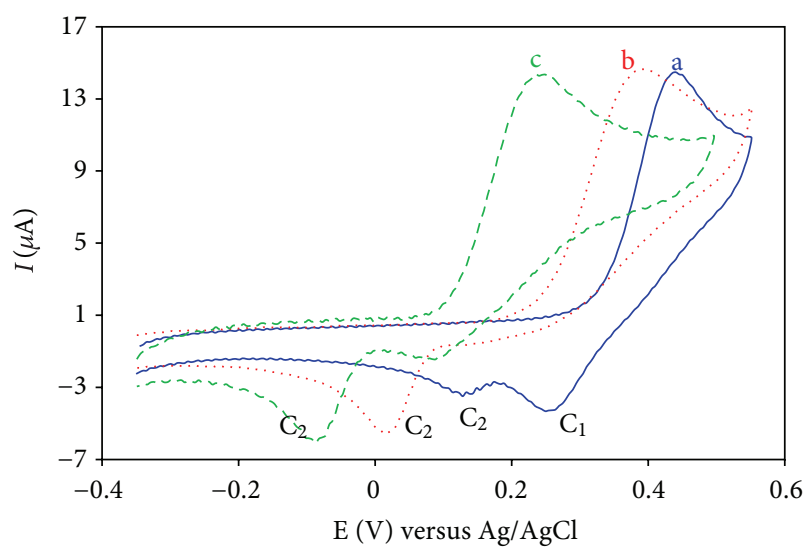

FIGURE 4: Cyclic voltammograms of $1.0 \mathrm{mM} 4$-methylcatechol and $1.0 \mathrm{mM} \mathrm{N}$-methylaniline at various $\mathrm{pH}$ values: (a) 4, (b) 6.0, and (c) 8.0 , scan rate $200 \mathrm{mV} \mathrm{s}^{-1}$.

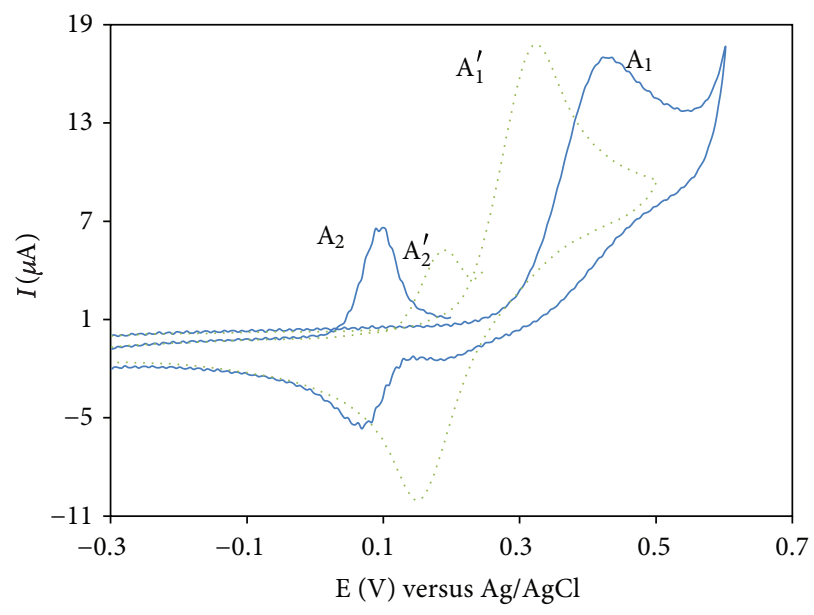

FIGURE 5: The cyclic voltammograms of $1.0 \mathrm{mM}$ solution of catechol (line) and 4-methylcatechol (doted) in the presence of $1.0 \mathrm{mM}$ $\mathrm{N}$-methylaniline in phosphate buffer solution $\mathrm{pH}$ 6, scan rate $200 \mathrm{mV} \mathrm{s}^{-1}$.

As shown in Figure 6, there are good agreements between the simulated voltammograms with those obtained experimentally. The calculated homogeneous rate constants in the case of catechol and 4-methylcatechol are $1.23 \mathrm{M}^{-1} \mathrm{~s}^{-1}$ (R.S.D. $=6.2 \%$ ) and $0.42 \mathrm{M}^{-1} \mathrm{~s}^{-1}$ (R.S.D. $\left.=5.6 \%\right)$, respectively at $\mathrm{pH}$ 5. Also Figure 6 illustrates the plots of $k_{\mathrm{obs}}$ for Michael addition reaction as a function of $\mathrm{pH}$. The observed rate constant increases by increasing the $\mathrm{pH}$ up to $\mathrm{pH} 6$ values which is related to deprotonation of amine group; it also slightly decreases at the pHs more than 6 which may be explained by this fact that conversion of $o$-quinone to catechol in a chemical step needs protonium exchange. Finally the variation of $k_{\mathrm{obs}}$ and anodic-to-cathodic peak currents ratio are interestingly the same which supports the accuracy of digital simulation. 


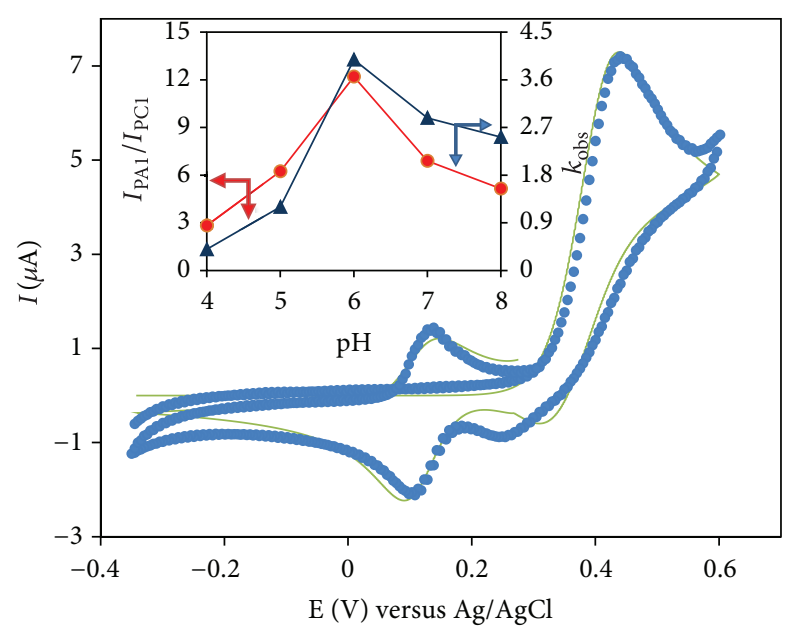

FIGURE 6: Simulated (doted) and experimental (line) cyclic voltammograms of catechol in the presence of $\mathrm{N}$-methylaniline at $\mathrm{pH} 4.0$, scan rate $100 \mathrm{mV} \mathrm{s}^{-1}$; inset: variation of peak current ration and observed rate constants versus solution $\mathrm{pH}$.

\section{Conclusion}

The results of this work show that catechol is oxidized in water to its respective $o$-quinones. The quinone is then attacked by $\mathrm{N}$-methylaniline to form catechol containing diphenylamine. The half-wave potential of these products is considerably less than catechols and they also converted to their quinone derivatives at the electrode surface. The half wave potential of these products strongly depends on their structures which depend on solution $\mathrm{pH}$ same as catechols. One of the most important parameters in antioxidant activity is the oxidation potential of the desired antioxidant; an implication of this study is the possibility of synthesis of structure and $\mathrm{pH}$ tunable compound with both catechol and diphenylamine groups. The antioxidants activity of these compounds will be a subject of interest, considering the possibility of formation of both phenoxyl and aminyl radicals. In addition, we have reported the quantitative study of reaction of $o$-quinones with $\mathrm{N}$-methylaniline at various $\mathrm{pH}$ values.

\section{Acknowledgment}

The authors of the paper do not have a direct financial relation with the commercial identity mentioned in the paper.

\section{References}

[1] B. A. Barner, "Catechol," in Encyclopedia of Reagents for Organic Synthesis, L. Paquette, Ed., John Wiley \& Sons, New York, NY, USA, 2004.

[2] L. Khalafi and M. Rafiee, "Kinetic study of the oxidation and nitration of catechols in the presence of nitrous acid ionization equilibria," Journal of Hazardous Materials, vol. 174, no. 1-3, pp. 801-806, 2010.

[3] R. H. Bisby, R. Brooke, and S. Navaratnam, "Effect of antioxidant oxidation potential in the oxygen radical absorption capacity (ORAC) assay," Food Chemistry, vol. 108, no. 3, pp. 1002-1007, 2008.

[4] M. Rafiee, "The electron: the simplest chemical reagent," Synlett, no. 3, pp. 503-504, 2007.

[5] D. Nematollahi, M. Rafiee, and L. Fotouhi, "Mechanistic study of homogeneous reactions coupled with electrochemical oxidation of catechols," Journal of the Iranian Chemical Society, vol. 6 , no. 3, pp. 448-476, 2009.

[6] D. Nematollahi and M. Hesari, "Electrochemical synthesis of amino-substituted 1,2-benzoquinone derivatives," Journal of Electroanalytical Chemistry, vol. 77, no. 2, pp. 197-203, 2005.

[7] D. Nematollahi, E. Tammari, S. Sharifi, and M. Kazemi, "Mechanistic study of the oxidation of catechol in the presence of secondary amines by digital simulation of cyclic voltammograms," Electrochimica Acta, vol. 49, no. 4, pp. 591-595, 2004.

[8] D. Nematollahi, A. Afkhami, F. Mosaed, and M. Rafiee, "Investigation of the electro-oxidation and oxidation of catechol in the presence of sulfanilic acid," Research on Chemical Intermediates, vol. 30, no. 3, pp. 299-309, 2004.

[9] O. Drzyzga, "Diphenylamine and derivatives in the environment: a review," Chemosphere, vol. 53, no. 8, pp. 809-818, 2003.

[10] S. Fujisawa, M. Ishihara, and Y. Kadoma, "Antioxidant activity of diphenylamine-related compounds as scavengers of carbon radicals," Internet Electronic Journal of Molecular Design, vol. 4, pp. 711-720, 2005.

[11] D. K. Gosser Jr., Cyclic Voltammetry: Simulation and Analysis of Reaction Mechanisms, New York, NY, USA, 1993.

[12] J. M. Saveant, Elements of Molecular and Biomolecular Electrochemistry, John Wiley \& Sons, Hoboken, NJ, USA, 2006.

[13] F. Marken, A. Neudeck, and A. Bond, in Electroanalytical Methods; Guide to Experiments and Application, F. Scholz, Ed., Springer, Berlin, Germany, 2002.

[14] M. Pelcova, E. Jiraskova, T. Nevecna, and J. Kulhanek, “The effect of substituents and the ionic strength on acid-base properties of substituted anilines," Acta Universitatis Palackianae Olomucensis Chemica, vol. 40, pp. 71-77, 2001.

[15] A. R. Campanelli, A. Domenicano, and F. Ramondo, "Electronegativity, resonance, and steric effects and the structure of monosubstituted benzene rings: an ab initio MO study," Journal of Physical Chemistry A, vol. 107, no. 33, pp. 6429-6440, 2003.

[16] L. Khalafi, M. Rafiee, and F. Yadaei, "Voltammetric study of the oxidation of quercetin and catechin in the presence of cyanide ion," Research on Chemical Intermediates, vol. 37, no. 8, pp. 1047-1055, 2011. 

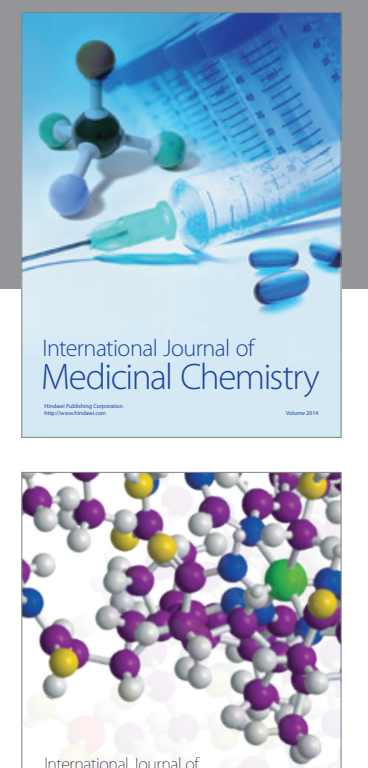

\section{Carbohydrate} Chemistry

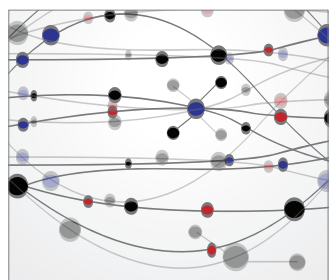

The Scientific World Journal
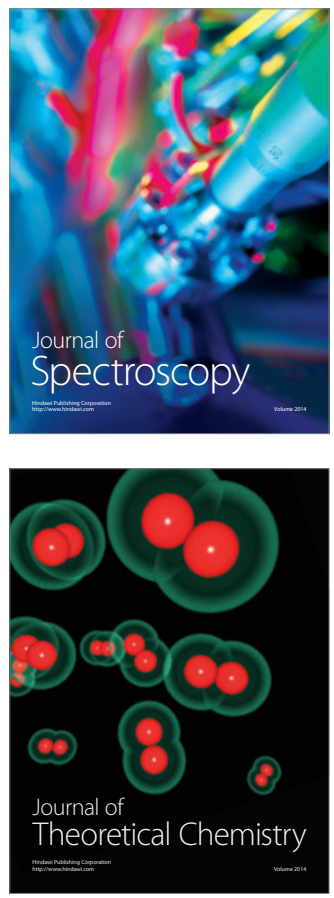
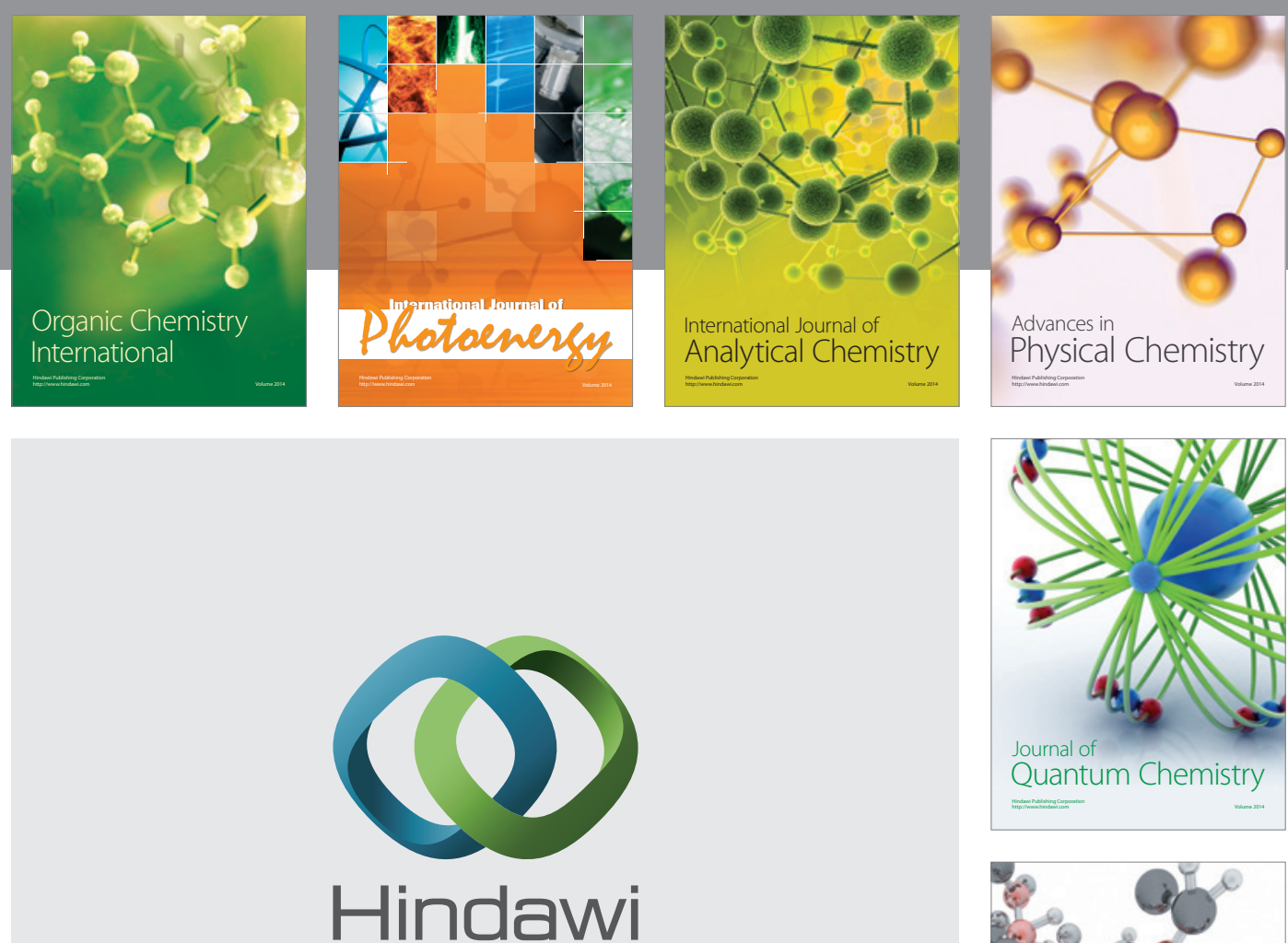

Submit your manuscripts at

http://www.hindawi.com

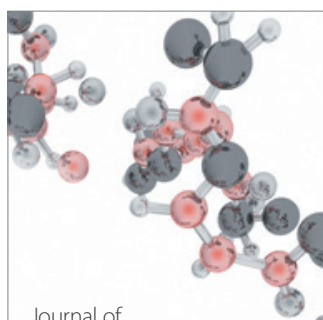

Analytical Methods

in Chemistry

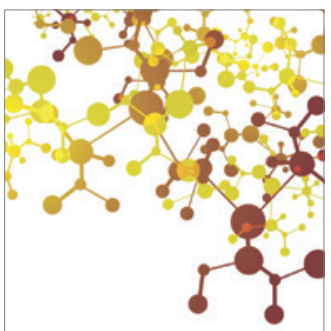

Journal of

Applied Chemistry

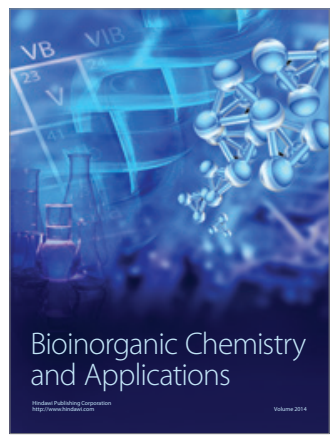

Inorganic Chemistry
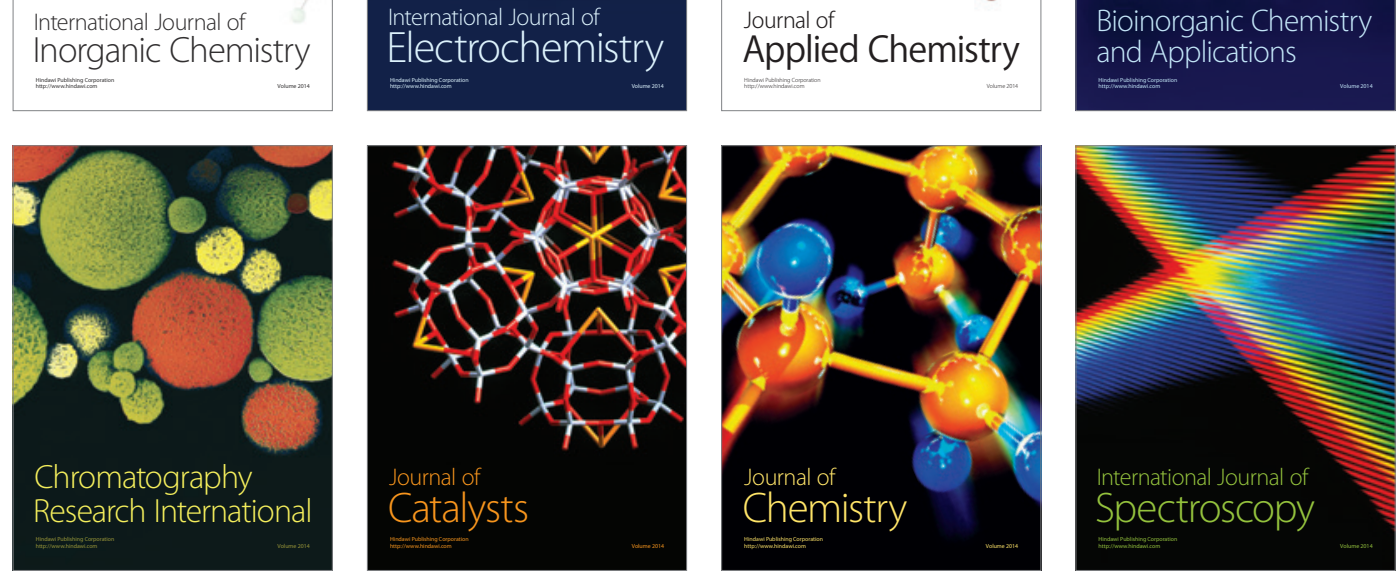